\title{
The effects of extended insulin dosage on target-directed attack and biting elicited by tailshock
}

\author{
STEPHEN F. DAVIS, JOHN K. GUSSETTO, and JAMES L. TRAMILL \\ Austin Peay State University, Clarksville, Tennessee 37040 \\ JERRY NEIDEFFER \\ Tarrant County Medical Education and Research Foundation, Fort Worth, Texas 76117
}

and

\author{
MARY NELL TRAVIS-NEIDEFFER \\ Texas Christian University, Ft. Worth Texas 76129
}

\begin{abstract}
Two studies relating extended insulin-dosage level to attack and biting elicited by tailshock are reported. In Experiment 1 four groups of rats received subcutaneous injections of 12, 16, 20 , or 24 units of regular zinc insulin, respectively, prior to shock testing. A fifth group served as an injection control. Response level for the 12-unit insulin group was significantly higher than for all other groups. Surprisingly, the response level of the 24-unit group was higher than that of the 16- and 20-unit groups. Dosage levels of 12, 28, and 32 units were employed in the second study to investigate this elevated responding. High and virtually identical response levels were shown by the 12- and 28-unit groups, with an extremely low response level being shown by the 32-unit group.
\end{abstract}

An expanding number of field studies, many of them conducted by Ralph Bolton (e.g., Bolton, 1973, 1976; Bolton \& Vadheim, 1973), have proposed a negative relationship between blood-sugar level and aggressiveness. Neideffer, Travis, Davis, Voohees, and Prytula (1977) experimentally investigated this proposed relationship. They reported that subjects with lowered blood-sugar levels (experimentally induced by insulin injections) displayed higher levels of attack and biting in the single restrained-animal, shock-elicited aggression situation than did subjects in an injection-control group.

Due to the fact that excessively high insulin levels result in debilitating effects such as insulin coma, it is possible that a different relationship might be obtained under more extreme doses than those employed by Neideffer et al. (1977). The present experiments were designed to more fully delineate this relationship.

\section{EXPERIMENT 1}

Three insulin-dosage levels $(4,8$, and 12 units) were employed in the Neideffer et al. (1977) study. In Experiment 1 insulin-dosage levels were extended to a

This research was sponsored, in part, by a Tower Fund research grant from Austin Peay State University to the first author. Portions of this paper were presented at the annual meeting of the Southern Society for Philosophy and Psychology, 1978. maximum of 24 units. More specifically, 12, 16, 20, and 24 units were administered to respective groups. An injection-control group received a comparable dose of Phenol (a carrier used in insulin preparations).

\section{Method}

Subjects. Forty male albino rats purchased from the Holtzman Company, Madison, Wisconsin, were randomly distributed across five groups $(n=8)$. All subjects were approximately 120 days old at the beginning of the experiment and were individually caged with water and food continuously available.

Apparatus. The shock-elicited-aggression apparatus (more fully described in Mollenhour, Voorhees, \& Davis, 1977) consisted of an opaque restraint tube, shock source, target rod, and impulse counter. The aggression target (Lafayette Instrument Company, Model 80111, omnidirectional lever) extended across the open midportion of the restraint tube. Attack upon the target rod activated the impulse counter, thus producing an automated record of the number of responses made by each subject. The subject's tail was extended through a small $(1.50-\mathrm{cm})$ hole in the other end of the restraint tube. A wood rod secured to the tail by adhesive tape prohibited escape from the restraint tube during shock testing. Two copper wires, permanently attached to the wood rod $7 \mathrm{~cm}$ apart, served as electrodes for the administration of tailshock.

Procedure. Subjects in Groups 12, 16, 20, and 24 had bloodsugar level reduced via corresponding subcutaneous injections of U-40 regular zinc insulin (regular Iletin, Eli Lilly \& Company). Subjects in Group C received an injection of $.06 \%$ Phenol and served as an injection-control group. To control for the volume of substance injected, all subjects received a 24-unit injection (i.e., subjects in Group 12 received 12 units of insulin plus 12 units of Phenol, subjects in Group 16 received 16 units of 
insulin plus 8 units of Phenol, and so forth). All injections were administered $1 \mathrm{~h}$ prior to testing. The injection schedule was staggered so that each subject had an individual testing session. The order for injecting, and hence the order for testing, subjects was determined by a table of random numbers.

An individual testing session consisted of securing the designated subject in the restraint tube $1 \mathrm{~h}$ after injection. Following a 5-min habituation period, the subject received 10 min of shock administration. During this time $2001.5-\mathrm{mA}$ (half-wave dc) shocks of $300-\mathrm{msec}$ duration were administered at 3-sec intervals. The number of responses made by each subject during the 10 -min test session was recorded.

\section{Results and Discussion}

The response data were converted to $\log _{10}\left(X_{i}+1\right)$ scores prior to analysis. Group mean responses are shown in Figure 1. A groups effect $[F(4,35)=3.46$, $\mathrm{p}<.05$ ] was yielded by an analysis of variance performed on this data. Subsequent Newman-Keuls tests indicated that Group 12 made significantly $(p<.05)$ more responses than did all other groups. No other significant differences were found.

In order to evaluate the possibility of weight-drug confounding, each subject was weighed just prior to receiving its injection. Group mean weights were as follows: Group C, $430.37 \mathrm{~g}$; Group 12, $429.75 \mathrm{~g}$; Group 16, $428.50 \mathrm{~g}$; Group 20, $431.37 \mathrm{~g}$; and Group 24, $423.75 \mathrm{~g}$. Analysis $\left(\mathrm{F}_{\max }\right.$, and one-way analysis of variance) of this weight data failed to yield significance.

As maximal responding was shown by Group 12, the results of the present study are supportive of the negative relationship proposed by Neideffer et al. (1977). However, the depressed performance shown by Groups 16, 20, and 24 suggests that a linear function may not completely describe this relationship.

\section{EXPERIMENT 2}

The increased responding shown by Group 24 in Experiment 1, although not statistically different from Groups C, 16, and 20, presented a potentially interesting

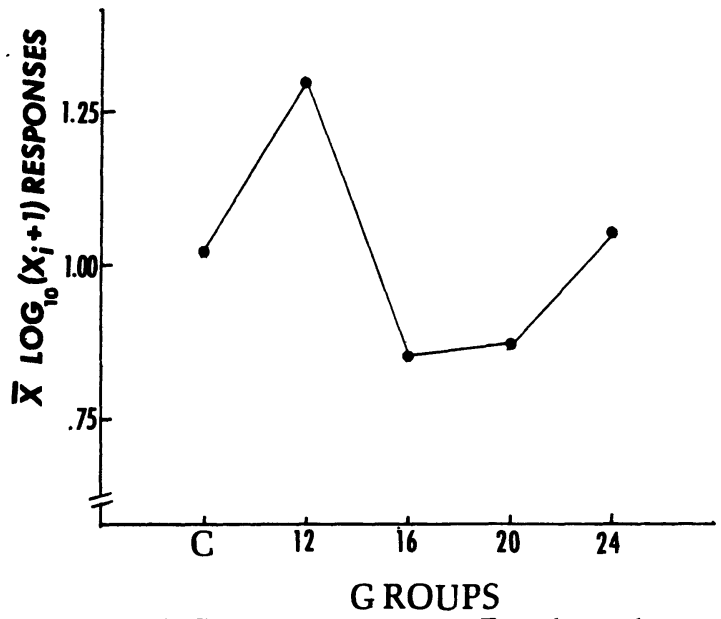

Figure 1. Group mean responses, Experiment 1.

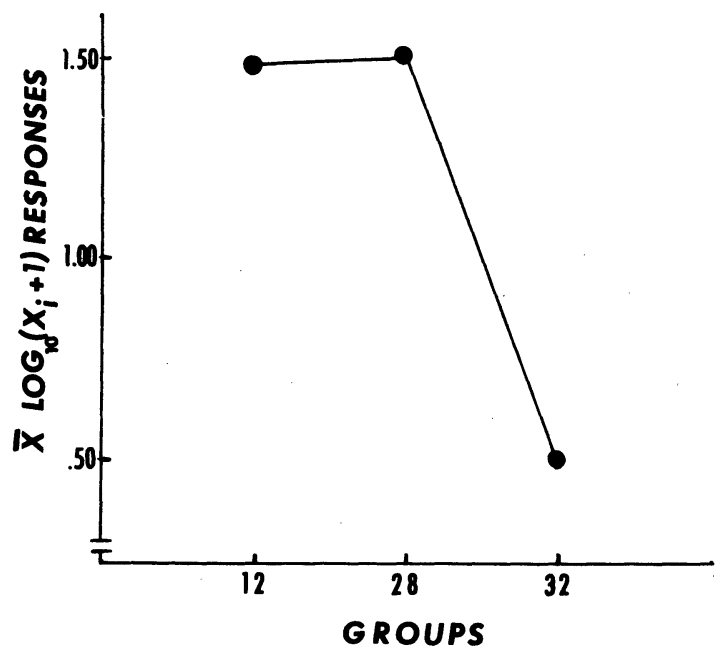

Figure 2. Group mean responses, Experiment 2.

problem. Would aggression continue to increase with increases in insulin dosage beyond 24 units? Experiment 2 sought to answer this question by testing two groups of rats injected with 28 and 32 units of insulin, respectively. As subjects receiving the 12-unit insulin injection had shown maximum responding in both the Neideffer et al. (1977) study and Experiment 1, a group receiving this dosage was also tested. It was felt that the responding of this group could be used both as a reference point for responding in the 28- and 32-unit groups and for futher corroboration of the results of the previous two studies.

\section{Method}

Subjects. Twenty-one male albino rats purchased from the Holtzman Company served as subjects. The subjects were approximately 120 days old and were housed as in Experiment 1.

Apparatus. The shock-elicited-aggression apparatus employed in Experiment 1 was used in Experiment 2.

Procedure. Three equal groups (Groups 12, 28, and 32) were randomly formed at the beginning of the experiment. Subjects in these groups received corresponding subcutaneous injections of U-40 regular zinc insulin (regular Iletin, Eli Lilly \& Company) to reduce blood-sugar level. To equate volume injected, an appropriate amount of Phenol was added to the 12- and 28-unit insulin injections so that all subjects received a 32-unit injection. Testing and randomization procedures were identical to those used in Experiment 1.

\section{Results and Discussion}

Prior to analysis the response data were converted to $\log _{10}\left(\mathrm{X}_{\mathrm{i}}+1\right)$ scores. Figure 2 shows group mean responses for Experiment 2. Analysis of variance yielded a significant groups effect $[\mathrm{F}(2,18)=11.71, \mathrm{p}<.01]$. Subsequent Newman-Keuls tests indicated that Groups 12 and 28 did not differ from each other, but responded significantly $(\mathrm{p}<.01)$ more than did Group 32 .

Weight data were recorded and analyzed to evaluate the possibility of weight-drug confounding. Group mean weights of $446.14 \mathrm{~g}$ (Group 12), $443.71 \mathrm{~g}$ (Group 28), 
and $445.71 \mathrm{~g}$ (Group 32) were obtained. As in Experiment 1 , analyses $\left(\mathrm{F}_{\max }\right.$, and one-way analysis of variance) of this weight data failed to yield significance.

Consistent with the findings of Neideffer et al. (1977) and Experiment 1, Group 12 displayed a high level of responding (see Figure 2). On the other hand, the equally high level of responding shown by Group 28 merits some consideration, especially in view of the lowered levels of responding shown by Groups 16, 20, and 24 in Experiment 1. Concerning a possible mechanism underlying this behavior, the following might be entertained. It is suggested that the blood-glucose level resulting from the 28-unit insulin injection was low enough to facilitate the release of glucagon by the pancreas. The glucagon, in turn, facilitated the breakdown of liver glycogen into glucose. The end result of this process was a rise in blood-glucose level. Thus, the functional blood-glucose level would appear, based upon the similarity of responding, to be quite similar for Groups 12 and 28. The low level of responding shown by Group 32 suggests that the debilitiating effects of high insulin level were being experienced by this group.

While the results of these two experiments are supportive of the negative relationship between attack and biting behavior and insulin dosage established by Neideffer et al. (1977), they also indicate that the correspondence is not perfect at all dosage levels. Further research employing different dosage levels (e.g., 10, 14, $18,22,26$, and 30 units appears warranted to more precisely define the nature of this relationship.

Although the present results, in concert with the
Bolton $(1973,1976)$ data, tempt one to generalize to aggressive behavior in humans, extreme caution should be exercised before this is done. Several reasons suggest such caution. First, additional animal research is needed to establish this relationship in other aggressive situations, such as the paired-animal footshock technique (see Ulrich \& Azrin, 1962). Second, determination of actual blood-sugar level needs to be made to verify the decreases that are only inferred at present. Such studies are currently in progress.

\section{REFERENCES}

Bolton, R. Aggression and hypoglycemia among the Qolla: A study in psychobiological anthropology. Ethnology, 1973, 12, 227-257.

Bolton, R. Hostility in fantasy: A further test of the hypoglycemia-aggression hypothesis. Aggressive Behavior, 1976, 2, 257-274.

Bolton, R., \& Vadheim, C. The ecology of East African homicide. Behavior Science Notes, 1973, 8, 319-341.

Mollenhour, M. N., Voorhees, J. W., \& Davis, S. F. Sleepy and hostile: The effects of REM sleep deprivation on shock-elicited aggression. Animal Learning \& Behavior, 1977, 5, 148-152.

Neideffer, J., Travis, M. N., Davis, S. F., Voorhees, J. W., \& Prytula, R. E. Sweet and sour rats: The effect of insulin dosage on shock-elicited aggression. Bulletin of the Psychonomic Society, 1977, 10, 311-312.

Ulrich, R. E., \& AzRIN, N. H. Reflexive fighting in response to aversive stimulation. Journal of the Experimental Analysis of Behavior, 1962, 5, 511-520.

(Received for publication April 12, 1978.) 